\title{
Artificial Intelligence for Health: Towards more intelligence or more artificial medicine?
}

\author{
Soto-Romero G*, Escriba C, Acco P, Campo E and Fourniols JY \\ LAAS-CNRS, Université de Toulouse, France \\ Submission: September 10, 2018; Published: October 04, 2018 \\ *Corresponding author: Soto-Romero G, LAAS-CNRS, Université de Toulouse, CNRS, INSA, ISIS Castres, 7, Av du colonel Roche 31400, France, \\ Tel: +33 5613362 00; Email: gsotorom@laas.fr
}

Keywords: Artificial Intelligence; Connected health; Medical devices

\section{Opinion}

If we refer to the latest studies on the use of artificial intelligence in health applications [1], we notice that different algorithms and software have been developed and tested in order to compare the results obtained between a human diagnosis and one given by a machine. As an example we can mention the recent competence in China in the diagnosis of brain tumors in which the Biomind system surpassed $87 \%$ of correct diagnoses to a group of surgeons, who achieved 66\% (out of 225 cases studied, in 15 'against 30 'respectively)[2].

Likewise, the new developments in medical robotics and connected objects for health advocate self-monitoring as a tool for the prevention of pathologies and as an element of conservation of autonomy for elderly patients, people with chronic pathologies and even as an element of physical activity promotion [3]. All this leads to the same conclusion: technology is part of medical practice and progressively generates physiological, biomechanical data and more that correctly analyzed give an assistance to the prevention, diagnosis and even treatment of patients.

These are the main benefits promoted by the defenders of this type of technology. Certainly supported by very real cases in low medical infrastructure countries or very rural areas, where technology allows to effectively solve problems due to the lack of doctors [4]. However, other studies question several elements about the obtained data: in some countries, the medical data is the patient's property who has the right to consult it anytime, which justifies a safe and reliable data storage. The use of these data by companies or thirds can lead to faults in medical secret and go against individual freedom.On the other hand, new studies show the lack of scientific validity and reliability in sensors and connected objects for health if the data obtained by these is compared with the data obtained by "gold standard" instruments in the clinical environment. Even, significant deterioration in the data isreported under real conditions of use, that is, in outside environment and normal movement conditions. The reduction of these artifacts and noise in the data is still a current scientific problem.

Finally, the accumulation of data obtained ends up representing a considerable burden for the clinical staff that must analyze and based on it establish a diagnosis or a therapeutic follow-up. Some rejection is even reported in the use of these new tools in already saturated services with regular activity [5] and it is recommended pretreatment of the data and extraction of pertinent indicators before requesting the clinical staff to give their expertise. As a result of this technology, innovative tools are used to train future doctors (thus avoiding tests on cadavers and patients with virtual reality technology and simulators) and to assist the clinical staff in general. This evolution is compared to the use of GPS, a machine that allows the user to be guided quickly and interactively for any displacement. In the last 10 years, GPS went from being an optional accessory for specific cases and for luxury cars to a tool so used that any Smartphone comes with it. If we follow this comparison, we would say that in cars as in pedestrians, GPS has become necessary and that has led to our almost inability to guide us by some other "old" or traditional method (road signs for example) to the point that memorizing a trip in advance, using a map or remembering points of interest has become a difficult task for the youngest. Has this evolution made us smarter or lazier?

Anticipating the arrival of intelligence on vehicles and the particular case of autonomous vehicles that do not need a driver, one can assume that in a few years it will not be necessary to teach to drive every young person as many of them will have AI to drive. And there will be said that machines are more reliable than humans to drive. But, will we be willing to let the future doctors not to make any diagnosis without a machine that supports them? Or even that it is a machine and not a human that takes care of 
us and gives us a medical prescription? The medicine of the next years will be more intelligent for humans or more artificial and done by machines?

It would be sad that behind all the development of artificial intelligence for health, it will lead to the impoverishment of our intellectual capacities for the benefit of the machine. Let's compare only our skill to perform mathematical operations without a calculator with our parents' skill, our ability to guide ourselves without a GPS in regard to our children's ability and we hope that the training of tomorrow's doctors does not follow the same path depending on the presence of $\mathrm{AI}$ in the process.

\section{References}

1. Ilyasova N, Kupriyanov A, Paringer R (2018) Particular Use of BIG DATA in Medical Diagnostic Tasks. Pattern Recognit Image Anal 28(1): 114-121.

This work is licensed under Creative Commons Attribution 4.0 License DOI: 10.19080/CTBEB.2018.16.555947
2. https://www.telegraph.co.uk/news/world/china-watch/technology/ artificial-intelligence-in-medicine/

3. Wang Z, Yang Z, Dong T (2017) A Review of Wearable Technologies for Elderly Care that Can Accurately Track Indoor Position, Recognize Physical Activities and Monitor Vital Signs in Real Time. Sensors 17(2): 341.

4. Nedungadi P, Jayakumar A, Raman R (2017) Personalized Health Monitoring System for Managing Well-Being in Rural Areas. J Med Syst 42(1): 22.

5. Peake JM, Kerr G, Sullivan JP (2018) A critical review of consumer wearables, mobile applications and equipment for providing biofeedback, monitoring stress and sleep in physically active populations. Front Physiol 9: 743.

\section{Your next submission with Juniper Publishers} will reach you the below assets

- Quality Editorial service

- Swift Peer Review

- Reprints availability

- E-prints Service

- Manuscript Podcast for convenient understanding

- Global attainment for your research

- Manuscript accessibility in different formats (Pdf, E-pub, Full Text, Audio)

- Unceasing customer service

Track the below URL for one-step submission https://juniperpublishers.com/online-submission.php 